\title{
Microtopographies control the development of basal protrusions in epithelial sheets
}

\author{
Sylvie Coscoy, ${ }^{1,2,3, a)}$ Sarah Baiz, ${ }^{4,5}$ Jean Octon, ${ }^{1,2}$ Benoît Rhoné ${ }^{4}$ Lucie Perquis, ${ }^{4}$ \\ Qingzong Tseng, ${ }^{1,2}$ François Amblard, ${ }^{1,2,6}$ and Vincent Semetey ${ }^{4, a)}$ \\ ${ }^{1}$ Laboratoire Physico Chimie Curie, Institut Curie, PSL Research University, CNRS UMR 168, 75005 Paris, \\ France \\ ${ }^{2}$ Sorbonne Universités, UPMC Univ Paris 06, 75005 Paris, France \\ ${ }^{3}$ Equipe labellisée "Ligue contre le cancer," 75005 Paris, France \\ ${ }^{4}$ Chimie ParisTech, PSL Research University, CNRS, Institut de Recherche de Chimie Paris, 75005 Paris, \\ France \\ ${ }^{5}$ Laboratoire Procédés et Ingénierie en Mécanique et Matériaux, PIMM, ENSAM, UMR 8006, CNRS, CNAM, \\ 151 boulevard de l'Hôpital, 75013 Paris, France \\ ${ }^{6}$ IBS Center for Soft and Living Matter, School of Life Sciences and Department of Physics, Ulsan National \\ Institute of Science and Technology (UNIST), 44919 Ulsan, South Korea
}

\begin{abstract}
Cells are able to develop various types of membrane protrusions that modulate their adhesive, migratory, or functional properties. However, their ability to form basal protrusions, particularly in the context of epithelial sheets, is not widely characterized. The authors built hexagonal lattices to probe systematically the microtopography-induced formation of epithelial cell protrusions. Lattices of hexagons of various sizes (from 1.5 to $19 \mu \mathrm{m}$ ) and 5-10 $\mu \mathrm{m}$ height were generated by twophoton photopolymerization in NOA61 or poly(ethylene glycol) diacrylate derivatives. The authors found that cells generated numerous, extensive, and deep basal protrusions for hexagons inferior to cell size $(3-10 \mu \mathrm{m})$ while maintaining a continuous epithelial layer above structures. They characterized the kinetics of protrusion formation depending on scaffold geometry and size. The reported formation of extensive protrusions in 3D microtopography could be beneficial to develop new biomaterials with increased adhesive properties or to improve tissue engineering.
\end{abstract}

\section{INTRODUCTION}

Cell behaviors, including cellular adhesion, morphology, cell function, migration, proliferation, cell and tissue organization, and differentiation, are regulated by the interactions between cells and their local microenvironments. Consequently, the chemical and mechanical properties and particularly the topographies of these microenvironments are important to regulate cell morphology and function. In organisms, cells are surrounded by three-dimensional scaffolds-e.g., extracellular matrix-which support, organize, shape, and guide them. These substrates present a huge variety of microtopographies: pores, ridges, grooves, or fibers, which have sizes in the nanometer to micrometer ranges. Despite reports on the importance of microtopography for some tissues, like bones (with microroughness favoring osseointegration ${ }^{1-4}$ ), the effects of topography upon implantation have remained largely unexplored for epithelial tissues. However, the precise knowledge of the effects of microtopography on cell behavior is required to provide innovative strategies to design medical implants in order to improve their integration or possibly suppress adverse reactions such as inflammation, as well as to develop scaffolds for tissue engineering and gain a better understanding of the biological phenomena involved.

\footnotetext{
a) Authors to whom correspondence should be addressed: sylvie.coscoy@curie.fr and vincent.semetey@chimie-paristech.fr
}

The development of microfabrication technologies (such as photolithography, ${ }^{5}$ electrospinning, ${ }^{6}$ colloidal templating, ${ }^{7}$ and two-photon polymerization ${ }^{8,9}$ ) allows the creation of two- or three-dimensional microtopographic features from a submicrometer scale to a scale of tens of micrometers, thus enabling us to mimic biological topographical features at specific length scales or replicate complex topographies in vitro with high precision and fidelity. Several reports in the literature using these technologies have shown that mammalian cells responded in vitro to topographical cues ranging from nanometer to mesoscale scales. ${ }^{10-12}$ Cell response to microtopography in vitro depends on cell type, feature size, shape, geometry, and physical and chemical properties of the substrate. One of the most well-known effects is contact guidance, in which cells respond to groove and ridge topography by simultaneously aligning and elongating $^{13-17}$ as well as migrating ${ }^{12,13,18,19}$ in the direction of the groove axis. Other groups have reported the guidance of axonal outgrowth along microtopographies like groove-ridge ${ }^{20,21}$ or pits. ${ }^{22}$ Microtopography can also induce different active cellular responses. It is able to cause cells to squeeze their nucleus ${ }^{23}$ or to increase fibroblast cell and nuclei volumes,${ }^{24}$ to control cell invasion initiated by chemotactic gradients in function of the size of the scaffold, ${ }^{25}$ and to finely control fibroblast geometric organization and mechanical constraints applied. ${ }^{26}$ Microtopography may also regulate cell differentiation. ${ }^{7,27-29}$ 
Epithelial cells can develop a wide range of membrane protrusions in order to sense their microenvironment and to adapt their function to it (mechanical action, control of the surface area for exchanges). While apical protrusions (contact with external media: microvilli, cilia, etc.) and lateral protrusions (lamellipodia and filopodia) are easily formed in classical 2D cultures, this is not the case for basal protrusions, not observed in vitro, because cells are usually seeded on planar coverslips. In vivo, basal membrane protrusions are important to sense basal matrix, ${ }^{30}$ particularly for a function of matrix degradation (invadopodia for cancerous cells, podosomes for some specialized cells, including osteoclasts, macrophages, and endothelial cells), ${ }^{31-33}$ but sophisticated basolateral infolds or interdigitations are also observed in vivo for a wide variety of nontransformed epithelial cells (e.g., proximal and distal renal tubule cells, choroid plexus, Malpighian tubule, salivary gland striated ducts, eye ciliary body). ${ }^{34-37}$ These different aspects led us to characterize the formation and behavior of membrane basal protrusions of epithelial cells seeded on substrates with regularly spaced hexagons, within a size range close to cell size.

In this paper, we studied how epithelial sheets respond to microtopography at their basal pole by extending protrusions. Microstructures were generated by two-photon polymerization, which allows the fabrication of any computer-generated 3D structure using ultrashort laser pulses, by direct laser writing into the volume of a photosensitive material. It produces microstructures with a high precision, offering the access to a wide set of microtopographies. ${ }^{38}$ In this study, we fabricated hexagonal lattices of various sizes $(D=1.5-19 \mu \mathrm{m}$, heights $H=5$ or $10 \mu \mathrm{m})$ made from NOA61 resin or poly(ethylene glycol) diacrylate (PEGDA) by two-photon photopolymerization in order to investigate the effect of microtopography on epithelial sheet protrusive response. The cell morphology (cell area and protrusion formation) and the actin cytoskeleton, as well as intercellular cell junctions on hexagonal scaffolds, were imaged and quantified in order to better characterize cellular response.

\section{MATERIALS AND METHODS}

\section{A. Materials}

Norland optical adhesive NOA61 was from Thorlabs. It was used directly on bare glass coverslips for two-photon photopolymerization.

PEGDA $(258,575)$ derivatives were purchased from Sigma-Aldrich (Saint-Quentin Fallavier, France) and were mixed to $5 \%(\mathrm{w} / \mathrm{v})$ of 2,2-dimethoxy-2-phenylacetophenone (Irgacure 651, Sigma-Aldrich) and protected from light before undergoing two-photon photopolymerization. PEGDA derivatives were used on silanized glass coverslips prepared as follows. Glass coverslips $(\varnothing=30 \mathrm{~mm})$ were first cleaned for 2 $\mathrm{h}$ in piranha solution to remove organic contaminants $\left(\mathrm{H}_{2} \mathrm{SO}_{4} /\right.$ $\mathrm{H}_{2} \mathrm{O}_{2}, 70: 30 \mathrm{v} / \mathrm{v}$-Warning: this is a highly corrosive solution). The substrates were then washed extensively with distilled water and dried under a filtered nitrogen stream. Cleaned wafers were exposed to monolayer deposition solutions prepared by mixing $100 \mu \mathrm{l}$ of 3-acryloxypropyltrichlorosilane with $100 \mathrm{ml}$ of dry 1,2-dichoroethane solvent at room temperature. The coating procedure was performed under an argon atmosphere. Samples were withdrawn from the silane solutions and washed several times with $\mathrm{CHCl}_{3}$ and ethanol and then dried under a nitrogen stream.

\section{B. Two-photon photopolymerization}

The setup consisted of a QSwitch Teem Photonics laser (Grenoble, France; $10 \mathrm{kHz}, 5 \mathrm{~ns}$ pulses, $10 \mu \mathrm{J}, 532 \mathrm{~nm}$ ), an IX70 microscope with a water objective 60× (NA 1.2; LPlanApo, Olympus), a piezo- $z$ stage and a 3D stage (Physik Instrumente), and a Guppy CCD camera for monitoring structure formation. It was driven by LITHOS software, with an autofocus module. ${ }^{39}$ Each structure was described as a succession of segments using a simple text file format generated with MATLAB (Mathworks) and converted using the SIMPOLY software.

After deposition on a $30 \mathrm{~mm}$ silanized or bare circular coverslip of one drop of, respectively, PEGDA or resin (NOA61), the initial $z$ position of the sample was adjusted so that the focal volume was just above the glass surface, and the microstructure was polymerized by moving the focal volume. Typical parameters used were as follows: laser power at the objective front aperture, $0.5 \mathrm{~mW}$; and exposure time, $4 \mathrm{~ms}$ (NOA61) and $6 \mathrm{~ms}$ (PEGDA). The formation of the structure was visualized in real time with the camera through the transparent coverslip, thanks to a change in the refractive index of the material as it polymerizes. After completion, structures were washed gently with $75 \mu$ l acetone and $75 \mu 1100 \%$ ethanol (for resin) or only ethanol (for PEGDA) and put into water. The two-photon microfabricated scaffolds were observed using a field emission gun scanning electron microscope (FEG-SEM LEO 1530, LEO Elektronenskopie $\mathrm{GmbH}$, Oberkochen, Germany) after the samples were gold sputtered [Figs. 1(b)-1(d)]. SEM imaging enabled the measurement of the structures' wall thickness (typically $1 \mu \mathrm{m}$ ), circumscribed diameter $D(1.5-19 \mu \mathrm{m}$, approximated to the nearest half-micron in the text), and height $H(5$ or $10 \mu \mathrm{m})$. The dimensions (height and width) given in the paper correspond to measurements by the SEM.

\section{Cell cultures}

Madin-Darby canine kidney (MDCK) and Michigan Cancer Foundation - 7 (MCF7) cells were grown in Dulbecco's modified Eagle's medium (DMEM) supplemented with $10 \%$ fetal calf serum, at $37^{\circ} \mathrm{C}$ and $5 \% \mathrm{CO}_{2}$, and $\mathrm{SW} 480$ cells in Leibovitz's L15 media $+10 \%$ fetal calf serum at $37^{\circ} \mathrm{C}$. Proximal convoluted tubule cells (PCTs, see the supplementary material $^{50}$ ) were grown in DMEM/F $12+1 \%$ fetal calf serum $2 \mathrm{mM}$ glutamine, $20 \mathrm{mM}$ HEPES, $5 \mu \mathrm{g} / \mathrm{ml}$ insulin, $50 \mathrm{nM}$ dexamethasone, $1 \mu \mathrm{g} / 1$ epidermal growth factor, $5 \mu \mathrm{g} / \mathrm{ml}$ transferrin, $30 \mathrm{nM} \mathrm{Na}$ selenite, $10 \mathrm{nM} \mathrm{T} 3$, and $125 \mu \mathrm{g} / \mathrm{ml}$ insulin. MDCK-Lifeact-green fluorescent protein (GFP) cells were obtained by stable transfection with Lifeact-GFP plasmid (Ibidi) as previously described ${ }^{40}$ and grown in complete media with $0.4 \mathrm{mg} / \mathrm{ml}$ geneticin (Invitrogen). MDCK E-cadherin-GFP cells were a kind gift from Nelson. ${ }^{41}$ PCT 
a

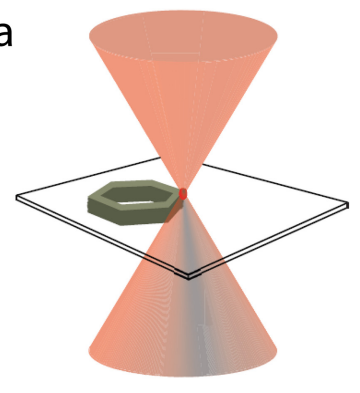

b

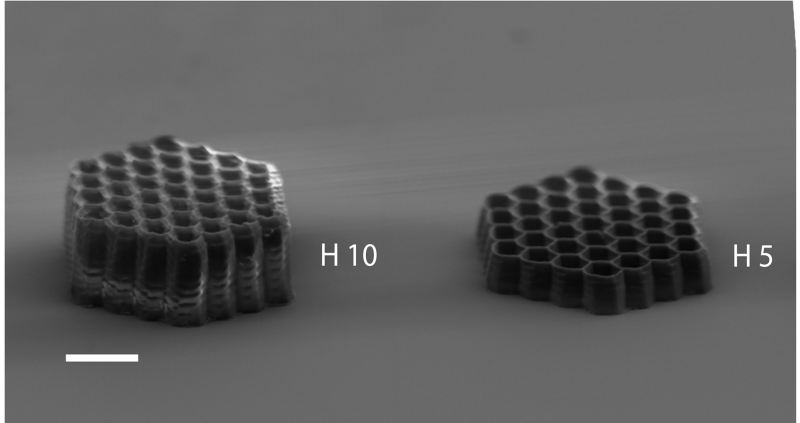

C
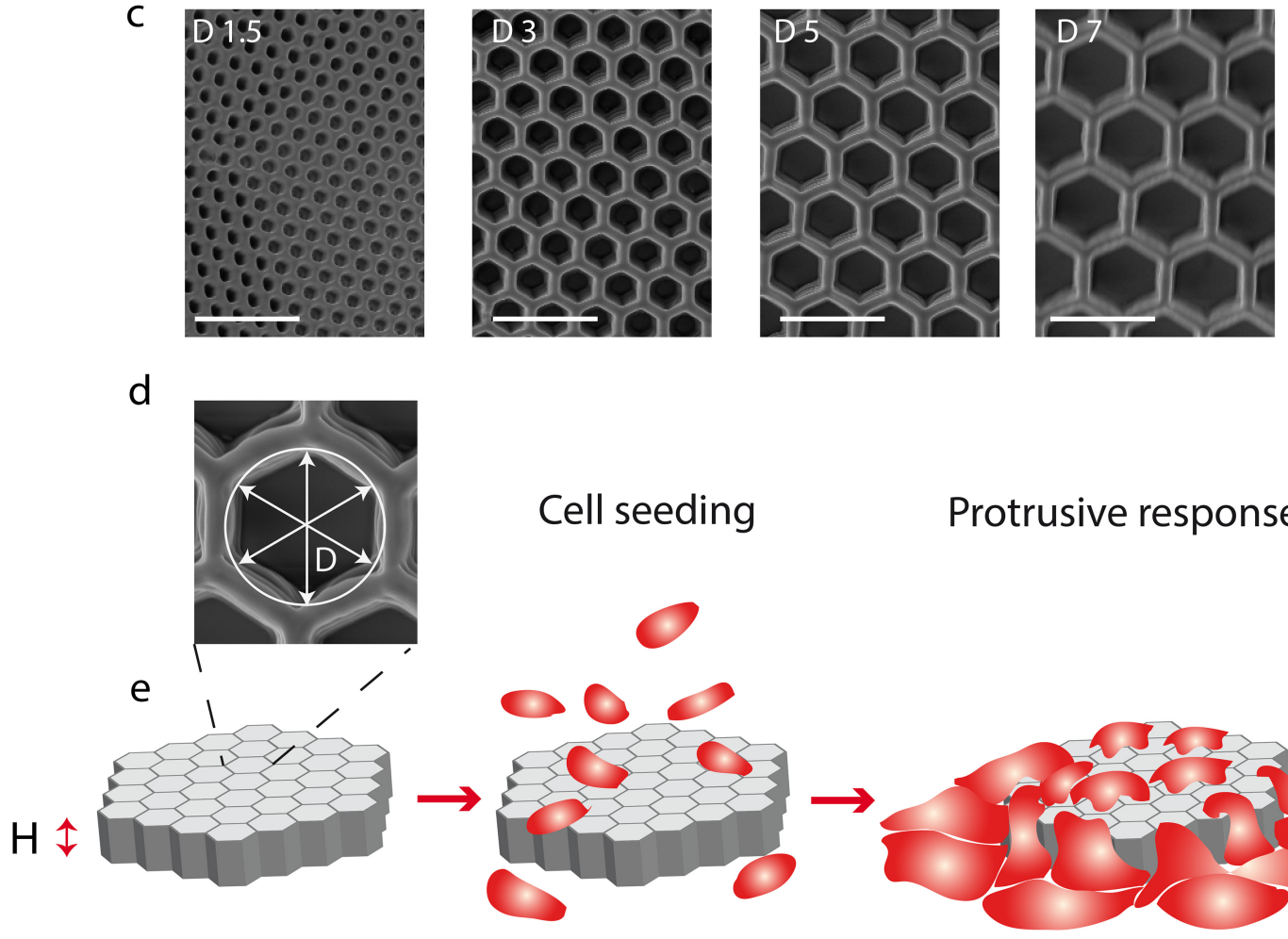

\section{Cell seeding}

\section{Protrusive response}

FIG. 1. (a) Principle of multiphoton polymerization generated by a focused laser beam. (b-d) SEM image of hexagonal microstructures fabricated by twophoton photopolymerization of NOA61 (scale bars are $10 \mu \mathrm{m}$ ). (b) Side view of arrays of hexagons of $D=3.5 \mu \mathrm{m}, H=5 \mathrm{or} 10 \mu \mathrm{m}$. (c) Top view of hexagonal structures of $D=1.5,3,5$, and $7 \mu \mathrm{m}, H=5 \mu \mathrm{m}$. (d) Definition of circumscribed diameter $D$, here $D=6 \mu \mathrm{m}$. (e) Principle of experiments: cells are seeded on top of hexagonal lattices with various sizes $D$ and heights $H$.

cells (mouse kidney proximal convoluted tubule cells) were a kind gift from Amanda Patel and Eric Honoré. SW480 and MCF7 cell lines transiently transfected with TRPV4 plasmids were used. Before seeding cells, structures were sterilized in ethanol, rinsed three times with phosphate-buffered saline (PBS), and a drop of concentrated cells $\left(1 \times 10^{6}\right.$ cells in $100 \mu \mathrm{l}$ of complete media) was deposited locally on top of structures and incubated for $2 \mathrm{~h}$ for initial adhesion, before the addition of $2 \mathrm{ml}$ of media for longer culture times.

\section{Labeling and imaging}

Cells on structures were fixed with $4 \%$ paraformaldehyde in PBS. Nuclei were labeled with $0.1 \mu \mathrm{g} / \mathrm{ml}$ Hoechst 34580
(Sigma). F-actin was either directly visualized in MDCKLifeact-GFP cells or labeled with $25 \mu \mathrm{g} / \mathrm{ml}$ phalloidintetramethylrhodamine isothiocyanate (TRITC, Sigma). E-cadherin was either visualized in MDCK E-cadherin-GFP cells or labeled by indirect immunofluorescence (with goat anti-E-cadherin primary antibody and Alexa 488 anti-goat IgG secondary antibody, Thermo Fisher). Ezrin and vinculin were labeled by indirect immunofluorescence, with respective primary antibodies: rabbit polyclonal anti-ezrin antibody, kindly provided by Monique Arpin, and monoclonal antivinculin antibody hVIN-1 (Sigma-Aldrich). Cell surface was labeled with fluorescent lectin after fixation and permeabilization [wheat germ agglutinin-fluorescein isothiocyanate (WGA-FITC), Sigma, $10 \mu \mathrm{g} / \mathrm{ml}$ ). After labeling, structures 
with cells were kept in PBS, and imaging was performed in PBS without mounting medium.

Confocal imaging was performed either on an inverted laser scanning confocal CLSM-LSM510 (Zeiss) with an Axiovert $200 \mathrm{M}$ microscope and $40 \times$ or $60 \times$ objective (NA 1.3-1.4), on an upright confocal spinning disk Roper/Zeiss with a NikonTE-2000-E microscope, Coolsnap HQ2 camera, and 40,60 , or $100 \times$ objective (NA 1.3-1.4), on an inverted spinning disk confocal Roper/Nikon with a Nikon TLE microscope, CoolsnapHQ2 camera, and 100× objective (NA 1.4) (Imaging Facility of Curie Institut-Nikon Imaging Center), or on a confocal TCS SP_CSU, with a resonant scanner $(12 \mathrm{kHz})$ and $63 \times$ objective, with $z$ compensation (Imaging Facility of Institute Pierre-Gilles de Gennes).

Images were analyzed with METAMORPH (Meta Imaging Series) or IMAGEJ softwares. Contrast optimization and denoising were performed for visual representation. Image denoising was performed with the IMAGEJ plugin Safir Filter developed by Jerome Boulanger. ${ }^{42}$ The protrusions, nuclei, and intercellular junctions present in each hexagon at specified heights were counted manually from fluorescence labeling. Experiments without confluent cell labeling around structures 1 day after seeding were not considered for analysis. Estimations for complete or incomplete coverage of hexagons were also performed manually from confocal images taking into account the shape of hexagons that was slightly visible by structure autofluorescence in UV images (used for nuclei visualization). To estimate the horizontal surfaces of individual cells (on flat surfaces or above structures), the largest possible area containing entire cells on the specified substrate was determined on confocal images, measured (on IMAGEJ), and the number of cells in this area was manually counted. Plots were realized with KALEIDAGRAPH or EXCEL softwares. Statistics ( $t$-tests) were performed in EXCEL. The errors indicated correspond to the standard error of the mean.

For surface area calculations, the theoretical basal 3D surface area corresponds to the sum of the horizontal area $A_{0}$ and the vertical surface covering the hexagon walls. The vertical surface area was deduced from the measured number of hexagons $N_{\text {hex }}$ in the specified area, multiplied by the interior area of each hexagon of length $a=D / 2$ and vertical height $H$ as follows: $S_{\text {theoretical }}=A_{0}+3 D N_{\text {hex }} H$. The experimental basal surface area was estimated by counting the number of hexagons $N_{i}$ inside which the cells extended to the maximal depth $H_{i}$, with the hypothesis that they uniformly covered walls (as visually observed, see Figs. 2 and 3): $S_{\text {experimental }}=A_{0}+3 D \sum_{i} N_{i} H_{i}$.

\section{RESULTS}

\section{A. Two-photon polymerization allows 3D microfabrication of hexagonal lattices}

In order to study the protrusive responses of cells in 3D microstructures exhibiting regular and well-defined microtopographies, we used two-photon photopolymerization [Fig. 1 (a)], which allows a resolution of the size of the voxel, $1 \mu \mathrm{m}$ in the $x y$ plane and $1.8 \mu \mathrm{m}$ in the $z$ plane. We studied the ability of cells to grow geometrically guided protrusions in vertical or horizontal tiny spaces. To this aim, we fabricated arrays of hexagons [Figs. 1(b)-1(d)] of different horizontal sizes $D$ (from 1.5 to $19 \mu \mathrm{m})$ and vertical elevation $H(H=5$ or $10 \mu \mathrm{m}$ heights), by two-photon polymerization of either NOA61 resin or PEGDA. The size $D$ refers to the mean largest internal dimension of the hexagons. It corresponds to the diameter of the circle circumscribed about the hexagon (without taking into account wall thickness $\sim 1 \mu \mathrm{m}$ ), i.e., $D=2 a$ with $a$ being the length of a hexagon side [Fig. 1(d)]. For the sake of simplicity in the text, we designated the structures by their $(D, H)$ characteristics expressed in $\mu \mathrm{m}$ (e.g., $D 7 H 5$ means $D=7$ and $H=5 \mu \mathrm{m}$ ). The microfabricated structures were observed by scanning electron microscopy (SEM) [Figs. 1(b)-1(d)]. Two-photon photopolymerization produced well-defined microstructures with a regular wall thickness of $\sim 1 \mu \mathrm{m}$. Microstructures were found to robustly resist the different washing steps, thanks to the rigidity of polymerized NOA61 or PEGDA (elastic modulus $>10 \mathrm{MPa}$ ). Cells were seeded on top of microstructures at a high density so that confluency was reached from the beginning of experiments. Cells were imaged at different times after seeding and adhesion [Figs. 1(e) and 2(a)]. Cell adhesion control experiments were performed by seeding cells either on spin-coated films or on two-photon photopolymerized flat films obtained by UV cross-linking of PEGDA or NOA resin. Adhesion of cells on the substrates was observed for both substrate types within $4 \mathrm{~h}$, thus showing the compatibility of such materials and surfaces with cell culture.

\section{B. Cells generate basal protrusions in hexagonal lattices}

We observed that the hexagonal lattices were rapidly colonized by a variety of epithelial cell lines (kidney, breast, and colon) within 1 day after cell seeding, with the formation of confluent monolayers above the structures. The most striking feature was the generation of numerous basal protrusions by the cells, filling completely all hexagons under optimal conditions [Fig. 2(a)]. We focused our study on the organization of renal MDCK cells (see Fig. 1 in the supplementary material ${ }^{50}$ for other cell types). On D7H5 hexagonal structures, confluent cell monolayers covered the top of the microtopography, where cells established intercellular adhesions visualized by F-actin labeling [Figs. 2(b)-2(d), right] and E-cadherin-GFP expression (see Fig. 2 in the supplementary material ${ }^{50}$ ), while retaining a correct apicobasal polarization (punctate actin organization at the apical side, and ezrin apical localization; punctate vinculin staining at basal side; see Fig. 2 in the supplementary material ${ }^{50}$ ). In agreement, conserved apicobasal polarization and tight junction formation were reported for MDCK on porous substrates with similar sizes. ${ }^{43}$

Inside hexagons, cells formed long, actin-rich protrusions in D7H5 structures, covering the whole microstructures by extending down to the glass bottom from 1 day after seeding, as visualized by F-actin staining [Figs. 2(c) and 2(d)] or cell surface staining with fluorescent lectin (see Fig. 2 in the 

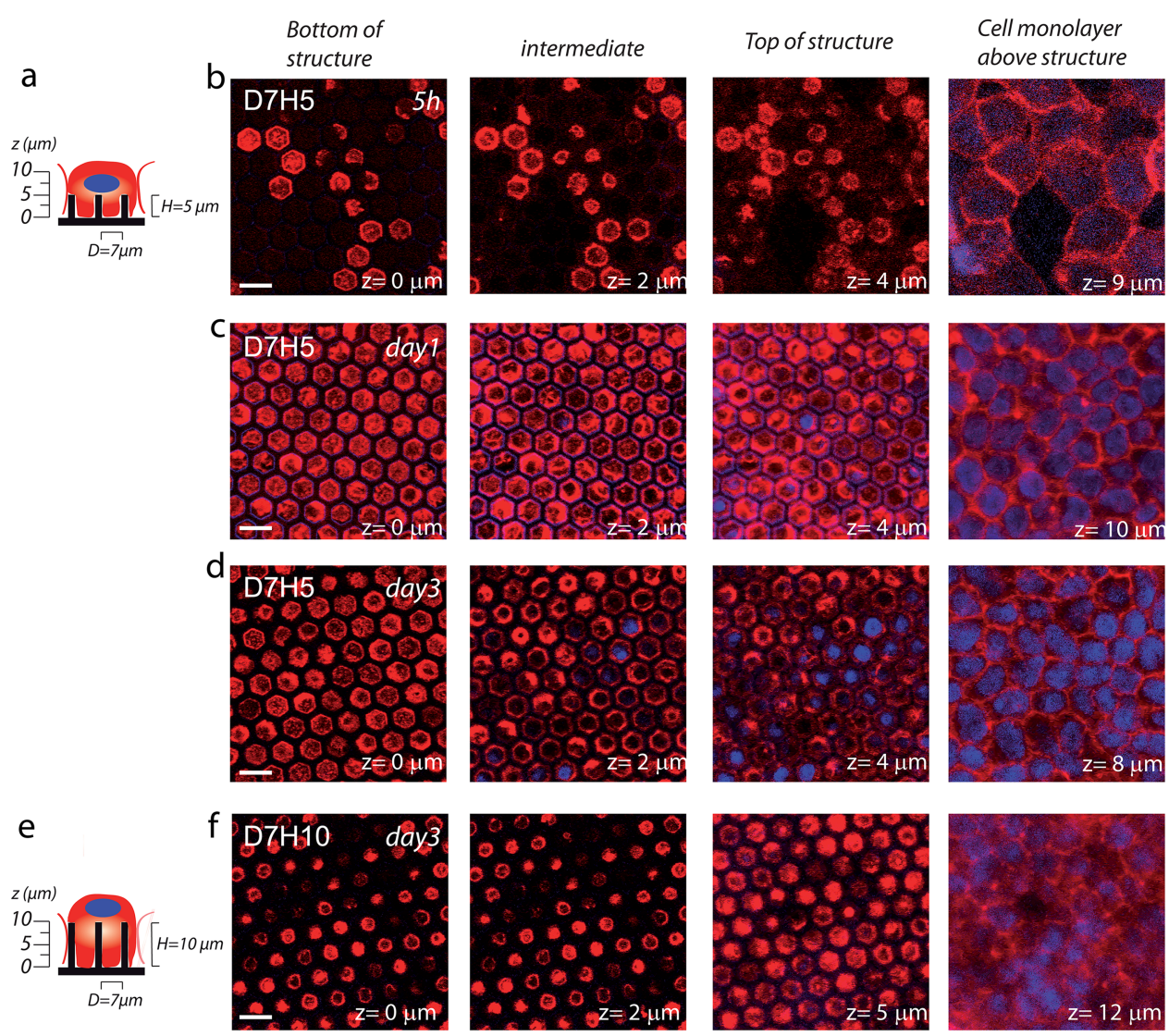

\section{g D7H5}

h $\mathrm{D} 7 \mathrm{H} 10$
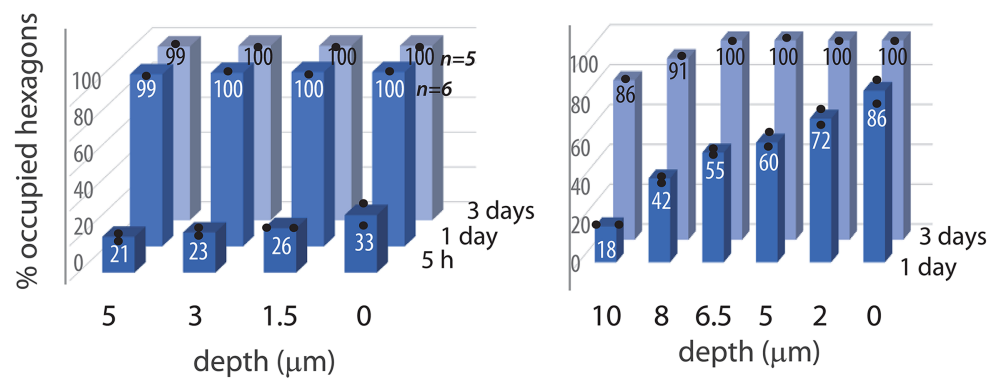

FIG. 2. Kinetics of protrusion formation in hexagons with $D=7 \mu \mathrm{m}$. (a and e) Principle of experiment and side view of basal protrusions: imaging is performed at sequentially increasing heights, illustrated here for $H=5$ (a) and $H=10 \mu \mathrm{m}$ (e). (b-d) MDCK cells were seeded on NOA61 hexagons $D=7 \mu \mathrm{m}$, $H=5 \mu \mathrm{m}$. They were fixed, stained for F-actin (red) and nuclei (blue), and imaged at $5 \mathrm{~h}$ (b, different $z$ planes), 1 day (c), or/and 3 days (d) after seeding. (f) Same experiments with $H=10 \mu \mathrm{m}, 3$ days after cell seeding. The scale bar represents $10 \mu \mathrm{m} . z=0$ corresponds to the basal plane of contact between cells and the coverslip surface. (g) Histogram of protrusion depths, measured from the top of the structure, for D7H5 condition, at $5 \mathrm{~h}, 1$ day, and 3 days after seeding. Percentage of occupied hexagons at a specified depth is indicated. (h) Histogram of protrusion depths for $D 7 H 10$ condition, at 1 and 3 days after cell seeding. ( $\mathrm{g}$ and $\mathrm{h}$ ) Mean values of independent experiments are represented. Black dots represent individual independent experiments, with measurements of whole fields of $\sim 130$ hexagons each. (g) The number of experiments is indicated for $n>2$. See Table 1 in the supplementary material (Ref. 50) for details.

supplementary material ${ }^{50}$ ). The kinetics of protrusion formation was studied by imaging cells $5 \mathrm{~h}, 1$ day, or 3 days after seeding [Figs. 2(b)-2(d)]. Partial protrusion formation occurred at an early time $(5 \mathrm{~h})$, in parallel to cell adhesion to the substrate; however, it concerned only $20 \%-30 \%$ of hexagons, with most of these protrusions extending to glass bottom reaching the maximal depth of $5 \mu \mathrm{m}$ [Fig. $2(\mathrm{~g})]$. This early stage was characterized by the existence of the vertical F-actin column at the protrusion center in a minority (about 20\%) of protrusions, and by the frequent incomplete filling of hexagons (in the cross section), reflecting a suboptimal adhesion with the substrate [Fig. 2(b)]. On the contrary, 1 day after seeding, hexagons became uniformly filled with protrusions [Figs. 2(c) and 2(d)], with all protrusions reaching the maximal depth [Fig. $2(\mathrm{~g}) ; 98.6 \pm 0.4 \%$ of hexagons completely covered with cell protrusions, in $n=6$ lattices of $\sim 130$ hexagons each; see Table 1 in the supplementary material $\left.{ }^{50}\right]$. Most of the results described in Secs. III C-III F refer to this set of parameters: hexagons of height $H 5(5 \mu \mathrm{m})$, imaging at day 1 after cell seeding, for which cells are fully engaged when hexagon horizontal size is $D 7$. 


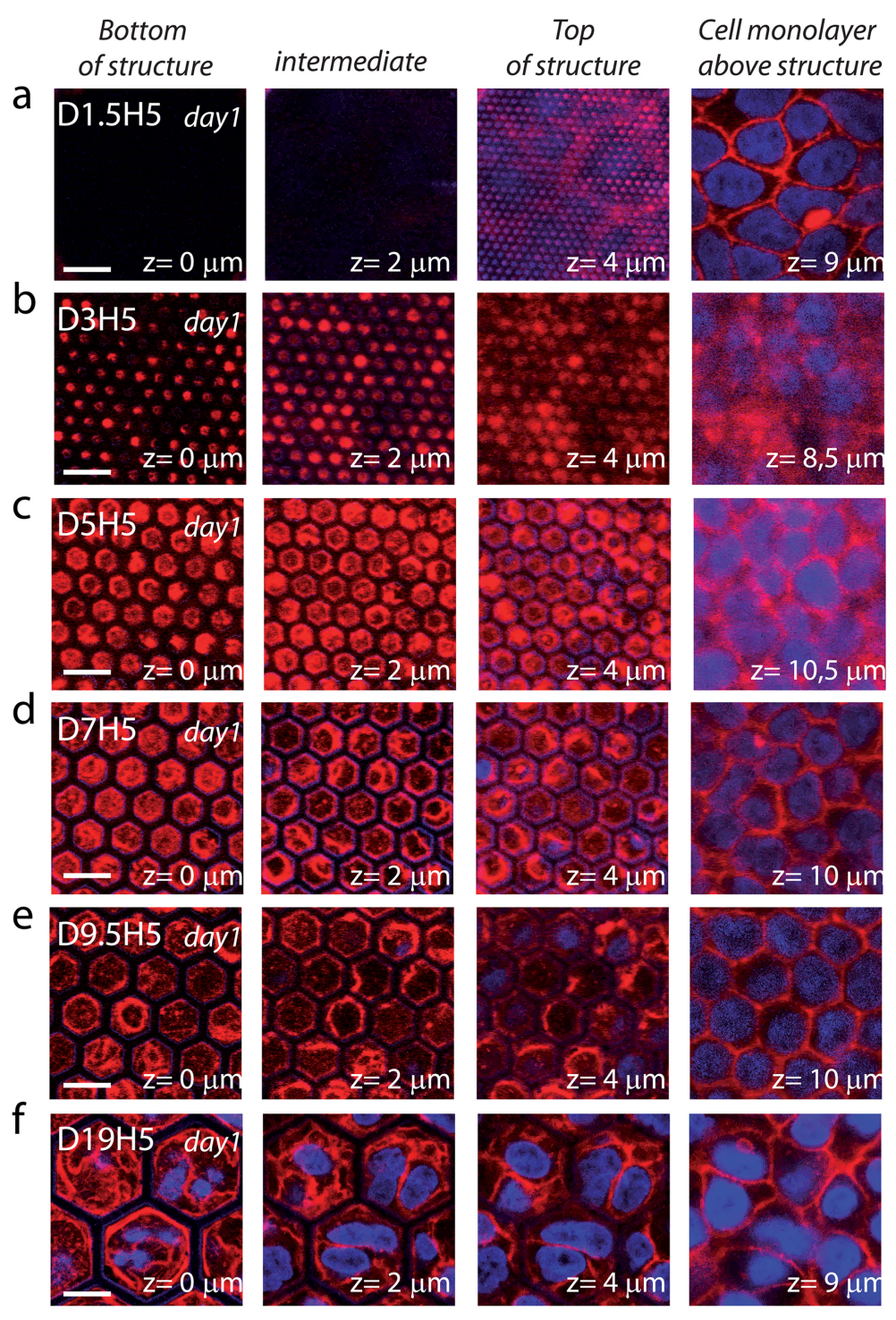

9

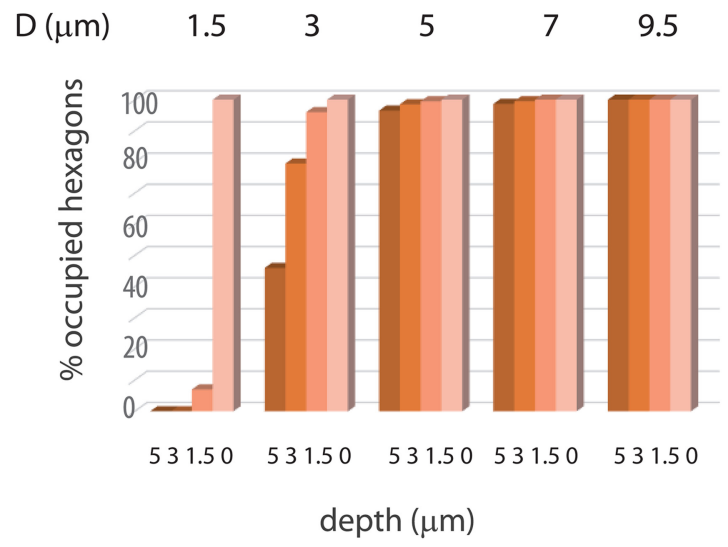

h

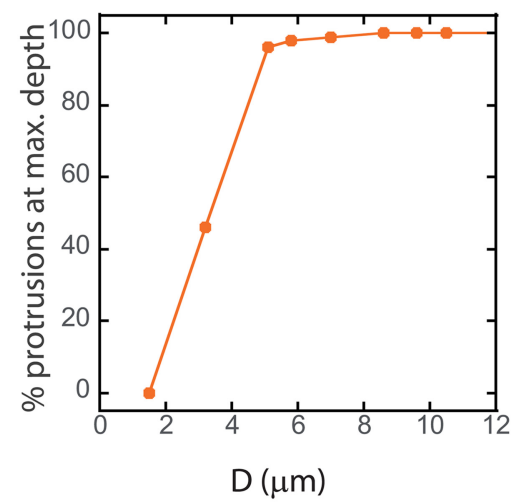

FIG. 3. Formation of protrusions as a function of the size of hexagons. MDCK cells were seeded on NOA61 hexagons, and fixed 1 day after seeding. Red: F-actin labeling (phalloidin-TRITC), blue: nuclei staining. Hexagons were of variable sizes $D$ with $H=5 \mu \mathrm{m}$. (a) $D=1.5 \mu \mathrm{m}$, (b) $D=3 \mu \mathrm{m}$, (c) $D=5 \mu \mathrm{m}$, (d) $D=7 \mu \mathrm{m}$, (e) $D=9.5 \mu \mathrm{m}$, and (f) $D=19 \mu \mathrm{m}$. The scale bar represents $10 \mu \mathrm{m}$. $z=0$ corresponds to the basal plane of contact between cells and the coverslip surface. (g) Depth histograms: percentage of occupied hexagons for different depths measured from the top of the structure, for a subset of $D$ values. Mean values of independent experiments are represented. See Table 1 in the supplementary material (Ref. 50) for details. (h) Percentage of fully occupied hexagons (depth $=5 \mu \mathrm{m}$ ) measured for $D$ values inferior to cell size. Each point corresponds to the mean of independent experiments, each consisting of measurements of all hexagons in one field of $92.5 \times 92.5 \mu \mathrm{m}^{2}$. See Table 1 in the supplementary material (Ref. 50) for details. 
Kinetics of protrusion formation was also studied for structures of higher height, i.e., D7H10 structures [Figs. 2(e) and $2(\mathrm{f})]$. In this particular case, protrusion penetration was only partial at day 1 , with about half of protrusions reaching 5-6 $\mu \mathrm{m}$ depth (in line with the fact that D7H5 protrusions were completely filled at this time) [Fig. 2(h)]. However, 3 days after seeding, cells succeeded in adapting the morphology of their basal side to fill most of the hexagons in D7H10 structures, while still maintaining a confluent organization on top of the structures [Figs. 2(f) and 2(h)].

\section{Formation of cell protrusions is a function of hexagon sizes}

We first studied cell responses when hexagon horizontal size $D$ ranges from 1.5 to $19 \mu \mathrm{m}$ for a fixed hexagon height H5. For small hexagons (D1.5), the cell monolayer did not penetrate significantly the array of hexagons although completely covering the top of the structure with the formation of intercellular contacts [Fig. 3(a)]. For larger hexagons (D3-D10), numerous protrusions were able to entirely fill a large majority of the hexagons, still with confluent cell monolayer above structures [Figs. 3(b)-3(e)]. This corresponds to the generation of $\sim 10$ protrusions per cell for the smallest structure $(D 3)$, to 1-3 protrusions per cell for the largest structures $(D 7-D 10)$. For $D 3$, protrusion engagement was still incomplete, with only half of the hexagons filled down to glass bottom, but all protrusions reaching at least $1-2 \mu \mathrm{m}$ depth [Fig. 3(g)]. From D5 to D10, a complete 3D coverage of hexagonal lattices with protrusions was observed [Figs. 3(c)-3(e), 3(g), and 3(h)].

For $D 11-D 13$, pores were large enough so that entire cells could fall inside them; however, epithelial cell sheet remained continuous above the structure, and cells extended some protrusions in adjacent hexagons (not shown). As hexagons size still increased (D13-D19), the geometry of cell organization on these structures appeared far more complex, with multilayered structures (cells in the hexagons, superior cell layer above the structures) and a complex array of interdigitated protrusions [Fig. 3(f)]. This is in line with the local formation of a multilayered structure when MDCK cells are confined to small circles in a $2 \mathrm{D}$ geometry $(100 \mu \mathrm{m}){ }^{44}$ The situation reported here is complementary because the configuration has no $2 \mathrm{D}$ limitation for the apical plane, but there is a narrow $3 \mathrm{D}$ confinement.

In conclusion, simple basal protrusions were observed from $D 3$ to sizes corresponding to cell size $(D 10-D 11)$ and were able to reach uniformly maximal depths of $5 \mu \mathrm{m}$ in D7H5 structures.

\section{Engagement of nuclei and intercellular junctions in hexagons}

In hexagons with large enough $D$, cells were able to partially engage specific structures like nuclei or intercellular junctions, while maintaining intact epithelial layers above the structure. This was here studied for a fixed height H5. The nuclei remained strictly above the structures for small $D[D 3$,
Fig. 4(a), left]. For larger $D(D 5-D 6)$, the nuclei still remained mostly in the upper plane but very partly engaged in hexagons [Fig. 4(a)]. This partial engagement concerned about a quarter of hexagons situated below a nucleus, and its depth was low in the order of $1 \mu \mathrm{m}$ [Figs. 4(b) and 4(c)]. This engagement became gradually more important when $D$ increased (D7-D8.5), although still concerning only $30 \%-40 \%$ of hexagons below a nucleus, with a maximal penetration depth of 2-3 $\mu \mathrm{m}$ [Figs. 4(a)-4(c)]. However, upon maturation of epithelial sheet (3 days after seeding) on D7H5 structures, nuclei engagement considerably increased [69\%, with some nuclei almost reaching glass bottom, Figs. 4(b) and 4(c)]. At last, a transition to an important nuclei engagement was observed from $D 9$ to $D 10$, with $70 \%-90 \%$ hexagons containing nuclei extending to more than $4 \mu \mathrm{m}$ [Figs. 4(a)-4(c)]. For $D \geq 11.5$, a complete nuclei penetration reflected the fact that cells began to fall entirely in the hexagons, as previously described (not shown). Such nuclei deformation in constrained topologies was previously reported in other studies reporting invasion assays in pores of adjustable $\operatorname{size}^{25}$ or cell organization between 4- $\mu$ m-spaced pillars. ${ }^{45}$

Interestingly, intercellular contacts were also able to extend all the way down to the hexagon bottom, as shown by F-actin labeling vertically extending from intercellular contacts above the structure to the bottom of structures [Fig. 4(d)]. Such structures were seen from D5 (while they may already exist for smaller $D$ but may be difficult to optically detect due to the small size of hexagons). They were present in 25\%-40\% hexagons located below an intercellular junction for $D 5-D 8.5$ after 1 day culture, with only a slight dependence on $D$, and in $45 \%-70 \%$ hexagons after 3 days of culture [Fig. 4(e)]. Values progressively increased for larger $D$, reaching more than $80 \%$ for $D>11$ (and $100 \%$ for $D 19$ with several cells in one hexagon) [Fig. 4(e)]. These close intercellular contacts, vertically extending in hexagons, suggested the existence of molecules involved in intercellular adhesion; however, a detailed molecular characterization remains to be made. E-cadherin extension in these vertical contacts was not systematic (Fig. 2 in the supplementary material $^{50}$ ), so these contacts may not be assimilated to adherens junctions. These contacts provide a potential interest by allowing several different, unconnected zones of contact between adjacent cells.

Characteristics of epithelial sheet organization in function of $D$ are summarized in Fig. 4(f). Protrusions extended from $D 3$ to $D 11$, with total cell engagement intermixed with protrusions from the above layer for larger $D$. Nuclei and intercellular junctions start to engage in protrusions from D5. These values have functional importance concerning adhesion and functional characteristics of epithelial sheets on structures.

The sizes used in our study were intermediate between ranges used in works with flexible pillars $(2-4 \mu \mathrm{m}$ periodicity), where cell-surface interactions take place only at the top of the micropillar array, ${ }^{46,47}$ and ranges used to reproduce the intestinal crypt structures $(50-500 \mu \mathrm{m}$ width, $120 \mu \mathrm{m}$ 
a
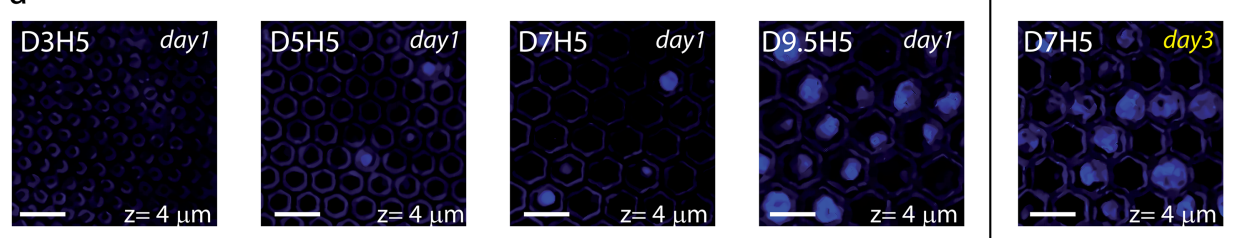

b \% of lattices containing part of a nucleus

C maximal depth reached by nuclei $(\mu \mathrm{m})$
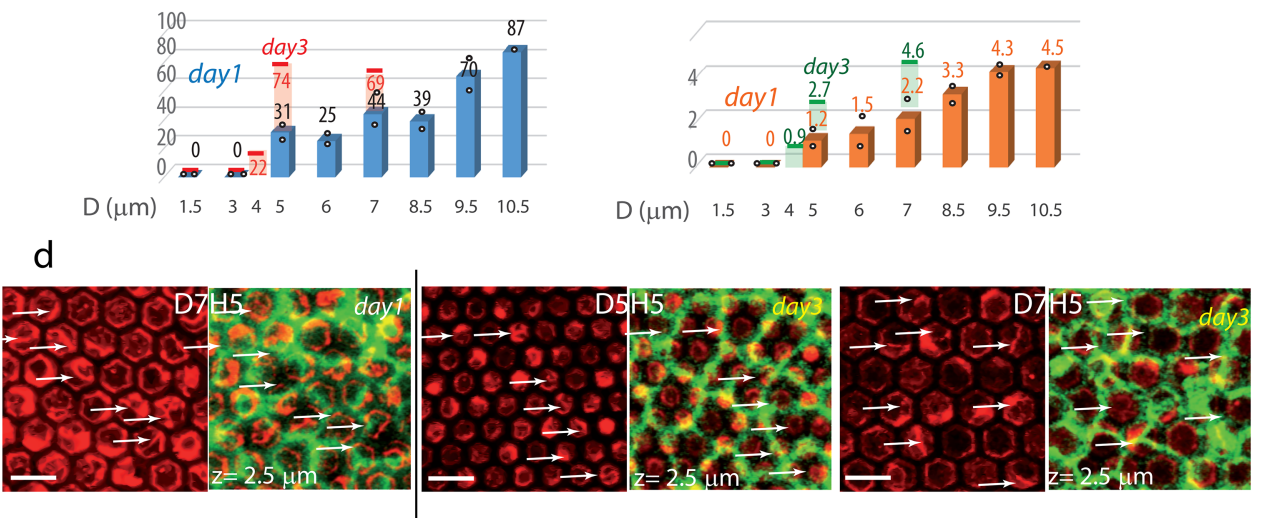

e

$\%$ of hexagons with junctions

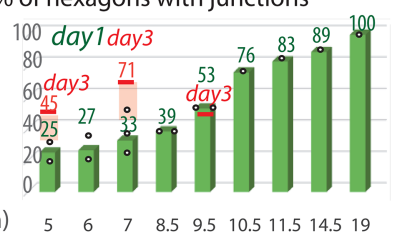

f

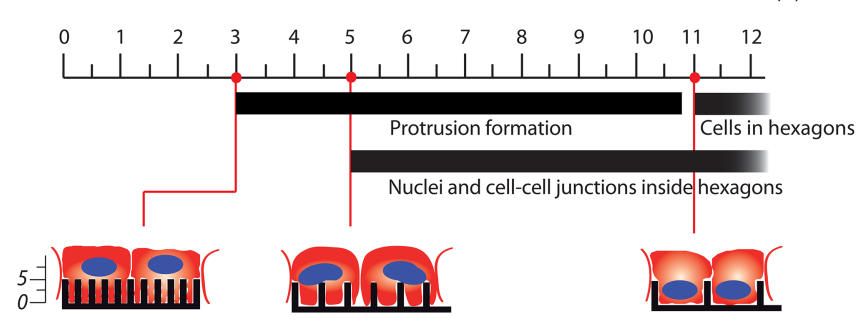

FIG. 4. Nuclei and intercellular junction engagement in hexagons, $H=5 \mu \mathrm{m}$, in function of $D$ size. (a) Nuclei (blue) engagement, images taken $1 \mu \mathrm{m}$ below the top of structures, showing a partial engagement: 1 day after seeding for $D=3,5,7$ and $9.5 \mu \mathrm{m} ; 3$ days after seeding for $D=7 \mu \mathrm{m}$. (b) Percentages of hexagons located below a nucleus, and containing part of this nucleus engaged inside (at $0.6 \mu \mathrm{m}$ depth), as a function of $D$. Blue: systematic study at 1 day, red: additional dots at 3 days. (c) Maximal depths reached by the nuclei at a function of $D$. This maximal depth may be attained by only a fraction of engaged nuclei. (b and c) Black dots correspond to measurements in one field of view of $92.5 \times 92.5 \mu \mathrm{m}^{2}$ (corresponding to 130 hexagons for $D 7$ ). Mean of two independent experiments is represented. See Table 1 in the supplementary material (Ref. 50) for details. (d) Intercellular junction engagement, 1 day (D7H5) and 3 days after seeding ( $D 5-D 7, H 5)$, measured $2.5 \mu \mathrm{m}$ below the top of the structure [image pairs corresponding to two different $z$ of one stack: left: F-actin labeling (red) in hexagons $(z=2.5 \mu \mathrm{m})$; right: F-actin labeling (green) showing intercellular junctions in top of the structure $(z>5 \mu \mathrm{m})$, superimposed with left image $(z=2.5 \mu \mathrm{m}$, still red)]. White arrows correspond to intercellular junctions extending in hexagons. (e) Percentages of hexagons with intercellular junctions above that have junctions extending inside, as a function of $D$, for 1 day seeding (green), with some points at 3 days of seeding for comparison (red). [Only hexagons with junctions above, green on (d) right, were considered, and tested for the vertical propagation of intercellular contacts, red in (d) right]. Black points correspond to measurements observed in one field of view of $92.5 \times 92.5 \mu \mathrm{m}^{2}$. Mean of two independent experiments is represented for $D<10$. See Table 1 in the supplementary material (Ref. 50) for details. (f) Recapitulative scheme of protrusion formation, and nuclei and junction engagement as a function of $D$, for $H=5 \mu \mathrm{m}$. The scale bar represents $10 \mu \mathrm{m}$. $z=0$ corresponds to the basal plane of contact between cells and coverslip.

depth), ${ }^{30}$ large enough so that a part of individual cells can settle initially in the bottom of wells, before migrating along walls. Pillar widths in the same spatial range of our study $(4 \mu \mathrm{m})$ led to deformations of osteosarcoma cell bodies and nuclei ${ }^{45}$ and to fibroblast spreading around pillars. ${ }^{48} \mathrm{~A}$ work on MDCK cells on porous materials, with holes between 0.45 and $5.5 \mu \mathrm{m}$, showed that cells grown over pores were less stiff and more fluid than cells on nonporous substrates; however, no deep protrusions seemed to be formed, which may be due to pore depth or substrate. ${ }^{43}$ In larger pores of 
$50-500 \mu \mathrm{m}$ width, cells generated protrusions of various thickness to sense their environments, in particular, protrusions horizontally bridging wells. ${ }^{30}$

\section{E. Extension to other substrates}

Results described so far correspond to the specific configuration of NOA resin built over bare glass, raising the question of the contribution of glass bottom to protrusion formation. To investigate this aspect, we generated arrays of hexagons on a glass slide previously fully covered with an NOA61 carpet of $2 \mu \mathrm{m}$ height. Carpets were produced by two-photon photopolymerization of parallel lines close enough $(1 \mu \mathrm{m}$ interval) to generate a full coverage. Cells adhered equally well to such a flat NOA61 carpet and to glass, as illustrated by Fig. 5(a), with a similar cell area (respectively, $186 \pm 4$ and $185 \pm 11 \mu \mathrm{m}^{2}$, obtained by measuring mean cell densities in $n=3$ and 2 fields). As compared with the isotropic appearance of F-actin filaments on bare glass, it can be noticed that cell cultures on NOA61 carpets displayed a slight alignment with the NOA lines used for carpet building, which is an illustration of the well-known contact guidance phenomenon [Fig. 5(a), right sides].

After formation of D7H5 or D7H10, NOA61 structures on NOA61 carpets, deep basal MDCK protrusions were observed, in a way similar to structures on bare glass [Figs. 5(b) and 5(c)]. For both D7H5 structures on NOA carpets and bare glass, the coverage of the hexagonal lattice was total with maximal protrusion depths, 1 day after seeding [Fig. 5(d)]. For D7H10 structures, the profile of protrusion depths (partial after 1 day seeding) was similar for NOA carpets and glass bottom [Fig. 5(e)]. This strongly suggests that glass bottom did not play a major role in stabilization of basal protrusions, which were produced to the same extent in a homogeneous NOA61 hexagonal lattice.

On the other side, we studied cell protrusion formation on another substrate. We generated D7H5 hexagons in PEGDA 575 (built on bare glass). Hexagonal arrays generated in PEGDA 575 were nicely defined, with thin walls, as displayed by the SEM [Fig. 5(g)]. After seeding of MDCK cells on D7H5 PEGDA 575 structures, we observed the generation of basal protrusions to a similar extent as NOA61, with similar depths after 3 days of seeding [Figs. 5(f) and 5(h)]. Epithelial sheet characteristics were similar as previously described for NOA61 substrates: confluent layer above structure with intercellular contacts, apicobasal polarity, and formation of basal protrusions as visualized with F-actin and fluorescent labeling (Fig. 3 in the supplementary material ${ }^{50}$ ). Also, protrusion characteristics were very close concerning kinetics ( $\sim 20 \%$ coverage $5 \mathrm{~h}$ after seeding, with partial guidance and transient formation of vertical F-actin columns, and good coverage 1 day after seeding - see surface labeling in Fig. 2 in the supplementary material ${ }^{50}$ ), characteristics (formation of intercellular contacts at later times), and dependence on $D$ size (Fig. 3 in the supplementary material ${ }^{50}$ ).

Finally, we tested the effect of an antiadhesive treatment, methylcellulose (MeCe). ${ }^{49}$ Coating various NOA61 hexagonal lattices (D3H5-D7H5) with a hydrophilic MeCe layer completely suppressed cell adhesion on structures (Fig. 4 in the supplementary material ${ }^{50}$ ).

In conclusion, the obtained results show that the formation and characteristics of basal protrusions do not depend primarily on the substrate used and may be a general property of rigid substrates.

\section{F. Characterization of the increase in basal surface areas}

Lattices of hexagons imposed a high increase in the 3D basal surface area of the epithelial sheet. Theoretical values for an increase in basal surface area assuming a full cell coverage were calculated [Fig. 6(a), blue, from the formula given in Sec. II]. For a fixed H5, the theoretical basal surface area was threefold higher than the projected flat area for D7H5 structures, where full coverage was quickly achieved; this increased gradually to an eightfold ratio for the smaller $D$ used (D1.5), in which incomplete penetration was observed [Fig. 3(a)]. Increasing $H$ instead of decreasing $D$ was another way to increase theoretical 3D basal area, here to a 4.8-fold ratio for $D 7 H 10$ structures [Fig. 6(b), blue], which could be fully colonized but at a lower rate [necessitating a cell adaptation of several days, as reported in Fig. 2 (g)].

Experimental measurements of the basal surface areas were performed [Fig. 6(a), orange, for H5 after 1 day seeding]. From $D 7$ to $D 3$, a high (threefold) increase in the experimental 3D basal surface area (compared to flat area) was observed. This value was constant for all $D$ values; it was similar to the theoretical maximal value for large $D$ (D5-D7), while it diverged from theoretical values associated with smaller $D$. This threefold increase might reflect the maximal ability of the cellular sheet to increase its basal surface area at short times. Accordingly, in the D7H10 structure after 1 day, where coverage was incomplete, the gain in the experimental basal surface area remained in the same range [3.1-fold, Fig. 6(b), yellow], in line with this model of a natural limitation of cell sheet reorganization. However, 3 days after seeding, cells were able to adapt to deeper structures and to cover largely the $D 7 H 10$ structure, leading to higher values of the increase in the basal surface area [4.7-fold, Fig. 6(b), orange]. Altogether, this very large increase in the basal surface area is expected to have major consequences on cell adhesion with the substrate and on cell exchanges.

At the level of an individual cell, this increase in the basal surface area was at least partly compensated by a decrease in the horizontal area or height of each cell. We studied in more detail the decrease in the horizontal area. (Note that a conservation of epithelial cell volumes in 3D topologies was reported in the literature, ${ }^{24}$ but detailed measurements of cell volume were not performed here because of technical limitations.) For $D 3-D 11.5$, where cells massively engaged basal protrusions, measurements of individual horizontal cell areas 
a

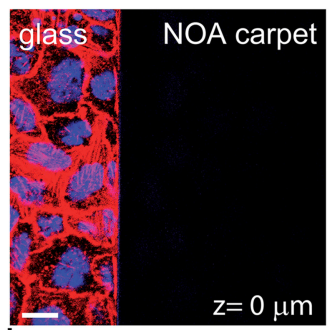

b

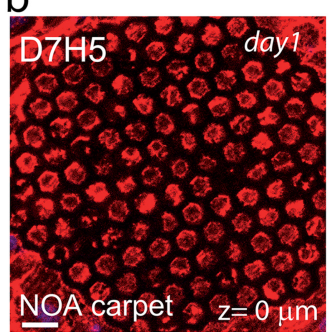

C

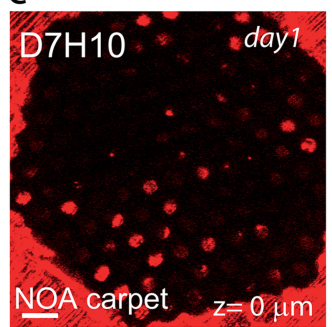

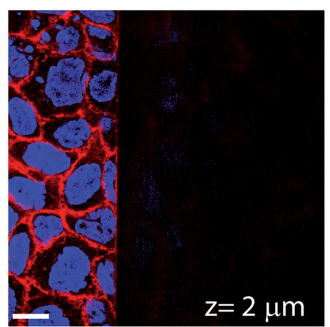
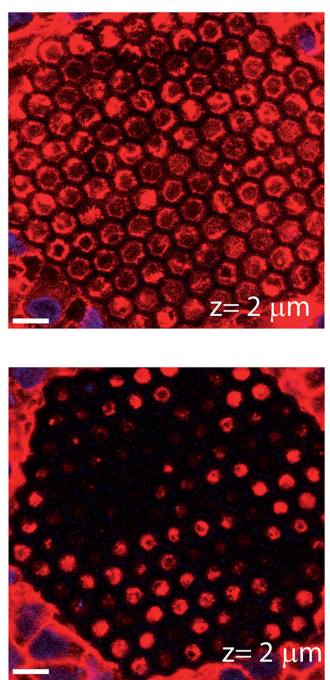
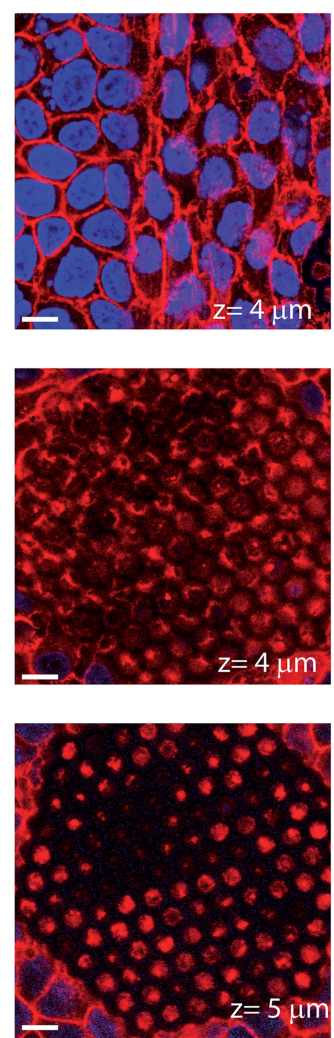
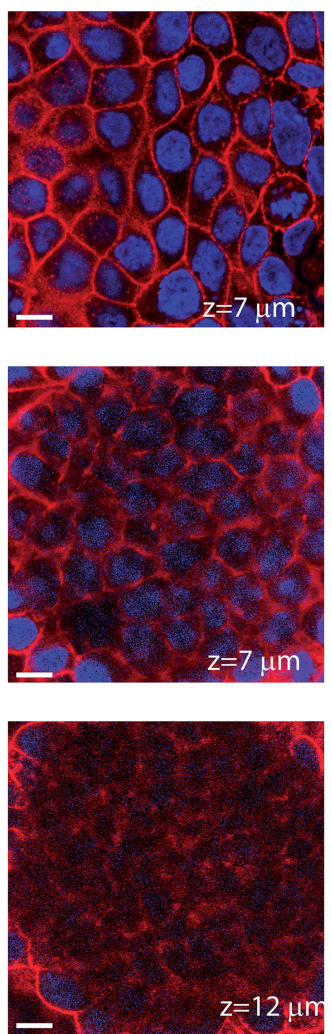

d

D7H5, NOA61

e

D7H10, NOA61

$f$

D7H5, PEG-DA575
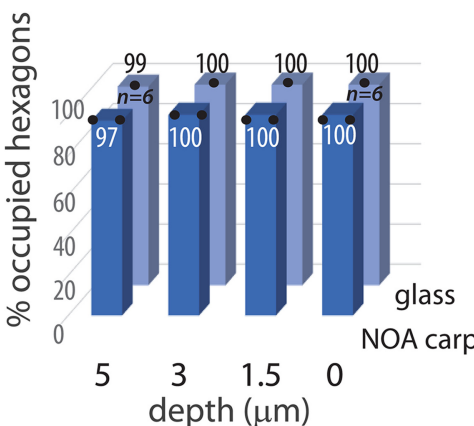

NOA carpet
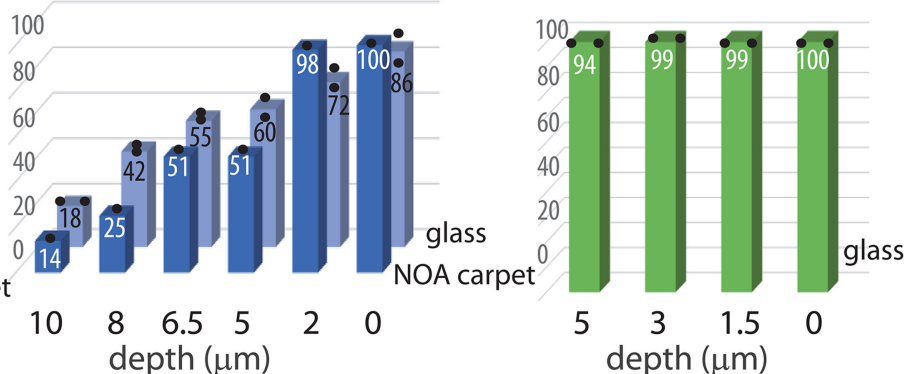

g
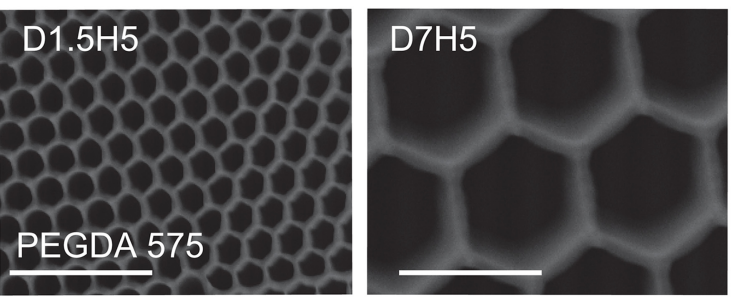

h
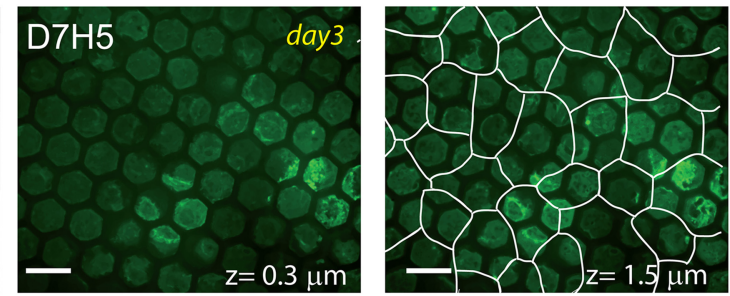

FIG. 5. Basal protrusions on NOA carpets and on the PEGDA 575 substrate. MDCK cells were fixed after 1 day (a-c) or 3 days seeding (h), and stained for F-actin (red) and nuclei (blue) (a-c), or endogeneously expressed Lifeact-GFP for F-actin visualization (green, h). (a) Cell behavior on NOA61 carpets (right) compared to adjacent glass (left). NOA61 carpet was generated by two-photon photopolymerization of adjacent vertical lines. (b) D7H5 NOA61 structure built on NOA61 carpet. (c) D7H10 NOA61 structure built on NOA61 carpet. (d) Depth histograms for cells on D7H5 NOA61 structures, built on bare glass or NOA61 carpet: percentage of occupied hexagons for different depths measured from the top of structure. (e) Depth histograms for cells on $D 7 H 10$ NOA61 structures, built on bare glass or NOA61 carpets. (f) Depth histograms for cells on D7H5 PEGDA 575 structures, built on bare glass. (d-f) Mean values of independent experiments are represented. Black dots represent individual independent experiments, with measurements of whole fields of about 130 hexagons each. The number of experiments is indicated for $n>2$. See Table 1 in the supplementary material (Ref. 50) for details. (g) SEM image of hexagonal microstructures D1.5H5 and D7H5 fabricated by two-photon polymerization of PEGDA 575. (h) MDCK-Lifeact-GFP cells seeded on PEGDA 575 (glass bottom). Cell contours (manually reported from cell organization in the plane above structure) are drawn. The scale bar represents $10 \mu \mathrm{m} . z=0$ corresponds to the basal plane of contact between cells and coverslip ( $a$ and $h$ ) or carpet (b and c). 

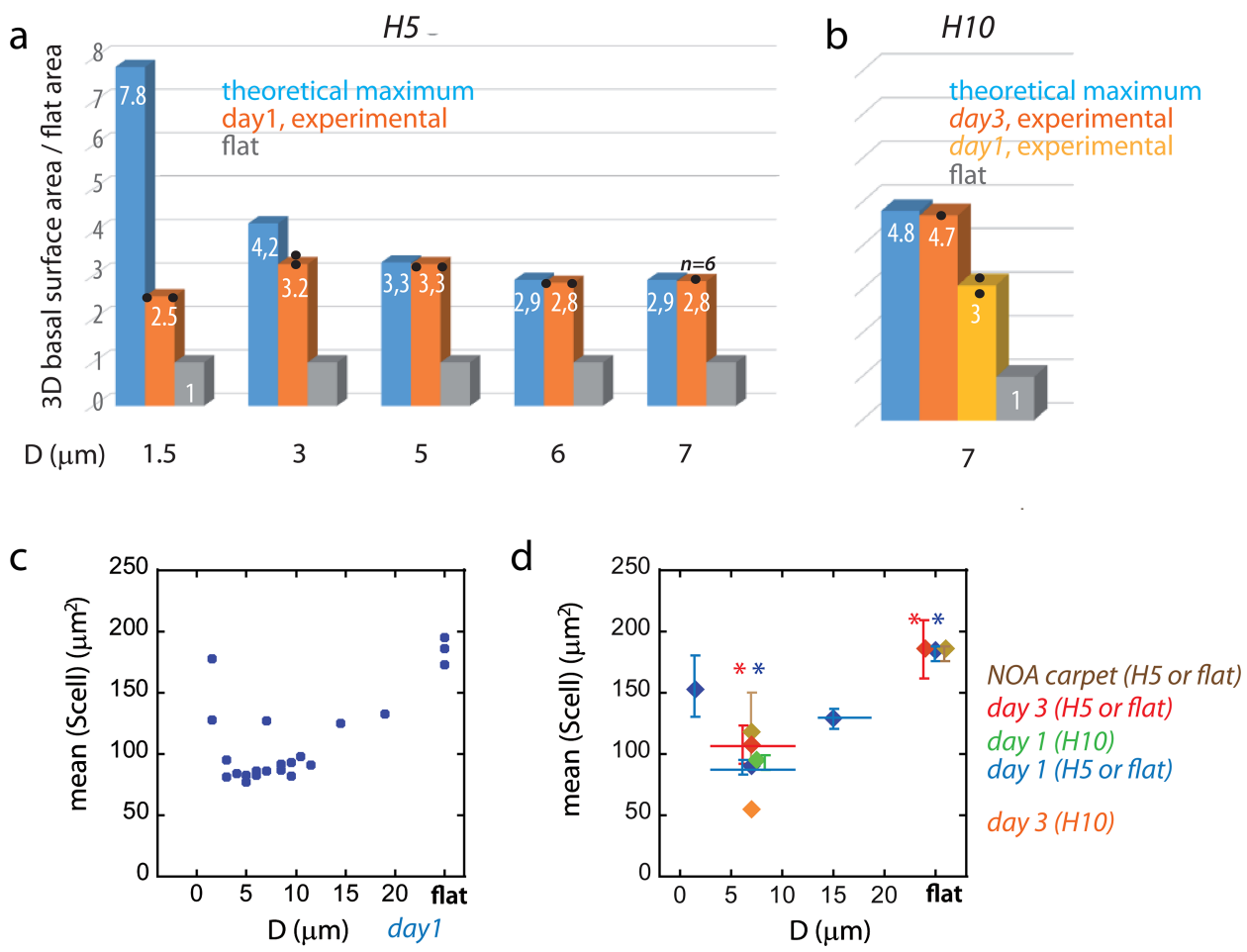

FIG. 6. Increase of basal surface area resulting from protrusion generation. (a and b) 3D basal surface areas of epithelial sheets [individual cell values are not considered here, see (c) and (d)]. Area values were normalized with respect to the flat area value $A_{0}$. (a) Theoretical maximal basal surface areas on lattices of hexagons (blue), experimental basal surface areas (orange) (and flat area, gray) were represented for $H 5$ structures with various $D, 1$ day after seeding (see calculation in Sec. II). (b) 3D basal surface areas of epithelial sheets on $D 7 H 10$ structures, axes are the same as in (a). Theoretical maximal basal surface areas on lattices of hexagons (blue), experimental basal surface areas after 3 days of culture (orange) or 1 day of culture (yellow) (and flat area, gray) are represented. (a and b) Experimental values correspond to the mean between independent experiments, see Table 1 in the supplementary material (Ref. 50) for details. Individual values are given. (c) Horizontal projected area of cells as a function of $D$, as determined from measurements of epithelial sheets above structures, as compared to the flat glass substrate. Measurements were performed 1 day after seeding, on NOA61 structures (on bare glass). One point corresponds to mean cell density in one field (of $92.5 \times 92.5 \mu \mathrm{m}^{2}$ ). (d) Horizontal projected area of cells for different $(D, H$, time) combinations. Brown: NOA carpet: flat (right) or $D 7 H 5$ (left), day 1. Red: day 3, flat (glass) (right), or (left) pool of $D$ values from $D 3 H 5$ to $D 11.5 H 5$ corresponding to the cases of protrusion formation. Green: D7H10, day 1. Blue: day 1: from left to right: $D 1.5 H 5$; pool of D values from $D 3 H 5$ to $D 11.5 H 5$ corresponding to the cases of protrusion formation; pool of $D$ values from $D 14 H 5$ to $D 19 H 5$; flat (glass). Orange: $D 7 H 10$, day 3. Each point corresponds to the mean between mean cell densities in different experiments (see text for detail: $n$ refers to $n_{\text {fields, }}$, the number of independent imaging fields of $92.5 \times 92.5 \mu \mathrm{m}^{2}$, inside which all cells were measured). Standard error of the mean is represented. * indicates a statistically significant difference between D3 and D11.5 lattices and glass, 1 day (blue) and 3 days (red) after seeding, with $p<10^{-3}$ and $p \sim 10^{-2}$, respectively.

(in the plane above structures) showed an almost constant twofold decrease compared to flat surfaces [Fig. 6(c)].

Mean horizontal surface areas, 1 day after seeding, were $185 \pm 6 \mu \mathrm{m}^{2}$ per cell, on bare glass (blue, right, $n=3$ ) versus $90 \pm 3 \mu \mathrm{m}^{2}$ for cells on $H 5$ structures with $D 3-D 11.5$ (blue, middle-left, $n=15$ ) [Fig. 6(d)]. As expected, horizontal areas became closer to those on bare glass, either for $D 1.5$ with very limited protrusion generation $\left(153 \pm 25 \mu \mathrm{m}^{2}, n=2\right.$; blue, left) or for $D 14-D 19$ where the above cell layer generated some interdigitated protrusion and established contact with the underlying cells in hexagons $\left(129 \pm 4 \mu \mathrm{m}^{2}, n=2\right.$; blue, middle-right) [Figs. 6(c) and 6(d)]. Similar values were observed 3 days after seeding, which may be due to the high initial cell density of cell seeding $\left[186 \pm 24 \mu \mathrm{m}^{2}, n=7\right.$, on glass (red, right) versus $108 \pm 15 \mu \mathrm{m}^{2}$ on $D 3-D 11.5$ structures, $n=16$ (red, left)], or on D7H5 structures on NOA61 carpets $\left(118 \pm 32 \mu \mathrm{m}^{2}, n=2\right.$, brown, left $)$ [Fig. 6(d)]. Horizontal areas were also measured on $D 7 H 10$ structures, where they were similar to $D 7 H 5$ after 1 day seeding and half penetration ( $95 \pm 1 \mu \mathrm{m}^{2}, n=2$, green) but decreased after 3 days of seeding and complete engagement $\left(55 \mu \mathrm{m}^{2}, n=1\right.$, orange), representing about one-third of the area on bare glass [Fig. 6(d)].

Epithelial cell sheets could achieve a total basal surface area increase either by increasing the cell number or by increasing the basal 3D surface area for each cell. Indeed, if strong limitations in the volume/surface area increase of individual cells existed, then it would be expected that the number of cells increases to compensate for that (for example, number of cells multiplied by 3 for a threefold increase in the basal cell surface area). Conversely, if the number of cells was kept constant (cells increasing their surface area/volume to compensate for what is engaged in microtopography), the density would be unchanged. Because epithelial sheets on $D 5 H 5$ to $D 11.5 H 5$ structures, where all the hexagons were fully filled with protrusions, showed a threefold increase in the 3D basal surface area compared to sheets on the flat surface, while their increase of the mean 
cell density was only twofold compared to sheets on the flat surface (bare glass), our results suggest that both cell number and 3D basal surface area per cell were increased on these structures. Values obtained for $H 10$ suggest that the increase in protrusion engagement at day 3 may be achieved by increasing the cell number, with a final situation that still necessitates an increase in individual basal 3D surface area compared to the flat situation. Thus, epithelial sheets were able to combine different ways of adapting to complex 3D architectures, with a high surface area increase as a result.

\section{SUMMARY AND CONCLUSIONS}

If it is well known that cells are able to generate various types of membrane protrusions modulating their adhesive, migratory, or functional properties, their ability to form basal protrusions, particularly in the context of epithelial sheets in response to their environment, remains, however, largely unexplored. In this work, we characterized the effects of 3D microtopography on cell geometrical organization and more precisely on the induced basal cell protrusions. We evidenced that the topography of lattices of hexagons exerted a strong influence on the cell protrusion generation ability. We observed the generation of massive deep actin-rich cell protrusions in both microstructures for tiny hexagons inferior to cell size. These protrusions completely filled the internal volume of hexagons, creating a surface contact area three times more important than the corresponding flat area. This study reveals the prominent ability of cells within the epithelial sheet to form extensive protrusions in response to welldefined three-dimensional microtopographies. From an in vitro point of view, the scaffolds described here constitute an original system to study membrane/cytoskeleton dynamics and intercellular adhesion, and it will be important to characterize cell dynamics during and after colonization of the lattices. Of particular interest is the fact that adjacent cells in the epithelial sheet are able to share an underlying hexagon with protrusions emanating from two to three cells, and propagating cell junctions, which may have significant effects in terms of junction stability. This study also suggests that the interactions between cells and biomaterials could be strongly reinforced by designing appropriate 3D microarchitectures that favor extensive protrusion formation, which might be useful in implant integration.

\section{ACKNOWLEDGMENTS}

The authors acknowledge the contributions of Miriam Nachi, Ashok Narladkar, and Taous Benarab for their help with experimental protocols and Olivier Cochet for cell line generation. They are very grateful to Isabelle Bonnet for writing specific image analysis code. They greatly acknowledge Fanny Cayrac and Anne-Christine Brunet for cell biology, Lucie Sengmanivong of the Nikon Imaging Centre at Institut Curie-CNRS, François Waharte and Vincent Fraisier from the PICT-IBiSA Lhomond Imaging facility of Institut Curie, Guillaume Lafitte for IPGG Imaging Facility, and Philippe Vermaut for scanning electron microscopy. The authors thank Laurent Malaquin, Pascal Silberzan, Axel Buguin and Matthieu Piel for discussions. They are grateful to Monique Arpin, Amanda Patel, Eric Honoré, and WJames Nelson for sharing biological material. This work was sponsored by an ANR grant (ANR-08-PCVI-0012-02), the CNRS (Centre National de la Recherche Scientifique) Chimie ParisTech and Institut Curie. The authors acknowledge the Cell and Tissue Imaging Facility of the Institut Curie (PICT), a member of the France BioImaging National Infrastructure (ANR-10-INBS-04). This work received the support of Institut Pierre-Gilles de Gennes (Equipement d'Excellence, "Investissement d'Avenir," program ANR-10-EQPX-34).

${ }^{1}$ D. M. Dohan Ehrenfest, P. G. Coelho, B. S. Kang, Y. T. Sul, and T. Albrektsson, Trends Biotechnol. 28, 198 (2010).

${ }^{2}$ B. Griffith, Manufacturing Surface Technology, Surface Integrity and Functional Performance (Butterworth-Heinemann, 2001).

${ }^{3}$ A. Wennerberg and T. Albrektsson, Clin. Oral. Implant. Res. 20(Suppl. 4), 172 (2009)

${ }^{4}$ O. E. Ogle, Dent. Clin. North Am. 59, 505 (2015).

${ }^{5}$ A. Mata, E. J. Kim, C. A. Boehm, A. J. Fleischman, G. F. Muschler, and S. Roy, Biomaterials 30, 4610 (2009).

${ }^{6}$ D. Grafahrend, K.-H. Heffels, M. V. Beer, P. Gasteier, M. Möller, G. Boehm, P. D. Dalton, and J. Groll, Nat. Mater. 10, 67 (2011).

${ }^{7}$ Y. C. Kuo and K. H. Chiu, Biomaterials 32, 819 (2011).

${ }^{8}$ K.-S. Lee, D.-Y. Yang, S. H. Park, and R. H. Kim, Prog. Polym. Sci. 33, 631 (2008).

${ }^{9}$ S. D. Gittard and R. J. Narayan, Expert Rev. Med. Devices 7, 343 (2010).

${ }^{10}$ C. J. Bettinger, Macromol. Biosci. 11, 467 (2011).

${ }^{11}$ K. W. L. Karina Kulangaraa, Soft Matter 5, 4072 (2009).

${ }^{12}$ R. G. Flemming, C. J. Murphy, G. A. Abrams, S. L. Goodman, and P. F. Nealey, Biomaterials 20, 573 (1999).

${ }^{13}$ A. I. Teixeira, G. A. Abrams, P. J. Bertics, C. J. Murphy, and P. F. Nealey, J. Cell Sci. 116, 1881 (2003).

${ }^{14}$ S. Chen, J. A. Jones, Y. Xu, H.-Y. Low, J. M. Anderson, and K. W. Leong, Biomaterials 31, 3479 (2010).

${ }^{15}$ A. Webb, P. Clark, J. Skepper, A. Compston, and A. Wood, J. Cell Sci. 108(Pt. 8), 2747 (1995).

${ }^{16}$ A. Wood, J. Cell Sci. 90(Pt. 4), 667-681 (1988).

${ }^{17}$ W. Hu, E. K. Yim, R. M. Reano, K. W. Leong, and S. W. Pang, J. Vac. Sci. Technol. A 23, 2984 (2005)

${ }^{18}$ B. A. Dalton, X. F. Walboomers, M. Dziegielewski, M. D. M. Evans, S. Taylor, J. A. Jansen, and J. G. Steele, J. Biomed. Mater. Res. 56, 195 (2001).

${ }^{19}$ C. J. Bettinger, Z. Zhang, S. Gerecht, J. T. Borenstein, and R. Langer, Adv. Mater. 20, 99 (2008).

${ }^{20}$ A. Rajnicek, S. Britland, and C. McCaig, J. Cell Sci. 110(Pt. 2), 2905 (1997).

${ }^{21}$ N. Gomez, Y. Lu, S. Chen, and C. E. Schmidt, Biomaterials 28, 271 (2007).

${ }^{22}$ J. N. Hanson, M. J. Motala, M. L. Heien, M. Gillette, J. Sweedler, and R. G. Nuzzo, Lab Chip 9, 122 (2009).

${ }^{23}$ F. Badique, D. R. Stamov, P. M. Davidson, M. Veuillet, G. Reiter, J.-N. Freund, C. M. Franz, and K. Anselme, Biomaterials 34, 2991 (2013).

${ }^{24}$ A. M. Greiner et al., Biomaterials 69, 121 (2015).

${ }^{25}$ A. M. Greiner, M. Jäckel, A. C. Scheiwe, D. R. Stamow, T. J. Autenrieth, J. Lahann, C. M. Franz, and M. Bastmeyer, Biomaterials 35, 611 (2014).

${ }^{26}$ A. C. Scheiwe, S. C. Frank, T. J. Autenrieth, M. Bastmeyer, and M. Wegener, Biomaterials 44, 186 (2015).

${ }^{27}$ A. Koroleva et al., PLoS ONE 10, e0118164 (2015).

${ }^{28}$ C. Y. Tay, H. Yu, M. Pal, W. S. Leong, N. S. Tan, K. W. Ng, D. T. Leong, and L. P. Tan, Exp. Cell Res. 316, 1159 (2010).

${ }^{29}$ E. K. Yim, S. W. Pang, and K. W. Leong, Exp. Cell Res. 313, 1820 (2007).

${ }^{30}$ L. Wang, S. K. Murthy, W. H. Fowle, G. A. Barabino, and R. L. Carrier, Biomaterials 30, 6825 (2009).

${ }^{31}$ C. Albiges-Rizo, O. Destaing, B. Fourcade, E. Planus, and M. R. Block, J. Cell Sci. 122, 3037 (2009) 
${ }^{32}$ M. Schoumacher, R. D. Goldman, D. Louvard, and D. M. Vignjevic, J. Cell Biol. 189, 541 (2010).

${ }^{33}$ K. van den Dries, M. Bolomini-Vittori, and A. Cambi, Cell Adh. Migr. 8, 268 (2014).

${ }^{34}$ D. B. Moffat, Yale J. Biol. Med. 49, 421 (1976).

${ }^{35}$ D. C. Pease, J. Cell Biol. 2, 203 (1956).

${ }^{36}$ F. S. Sjörstrand and J. Rhodin, Exp. Cell Res. 4, 426 (1953).

${ }^{37}$ L. W. Welling, D. J. Welling, J. W. Holsapple, and A. P. Evan, Am. J. Physiol. 253, F126 (1987).

${ }^{38}$ A. Marino, C. Filippeschi, V. Mattoli, B. Mazzolai, and G. Ciofani, Nanoscale 7, 2841 (2015).

${ }^{39}$ I. Wang, M. Bouriau, P. L. Baldeck, C. Martineau, and C. Andraud, Opt. Lett. 27, 1348 (2002).

${ }^{40}$ A. Gautreau, D. Louvard, and M. Arpin, J. Cell Biol. 150, 193 (2000).

${ }^{41}$ C. L. Adams, Y. T. Chen, S. J. Smith, and W. J. Nelson, J. Cell Biol. 142, 1105 (1998).

${ }^{42}$ C. Kervrann and J. Boulanger, IEEE Trans. Image Process. 15, 2866 (2006).
${ }^{43}$ J. Rother, M. Buchsenschutz-Gobeler, H. Noding, S. Steltenkamp, K. Samwer, and A. Janshoff, J. R. Soc. Interface 12, 20141057 (2015).

${ }^{44}$ M. Deforet, V. Hakim, H. G. Yevick, G. Duclos, and P. Silberzan, Nat. Commun. 5, 3747 (2014).

${ }^{45}$ M. Eichhorn, C. Stannard, K. Anselme, and J. Ruhe, J. Mater. Sci. Mater. Med. 26, 108 (2015).

${ }^{46}$ O. du Roure, A. Saez, A. Buguin, R. H. Austin, P. Chavrier, P. Silberzan, and B. Ladoux, Proc. Natl. Acad. Sci. USA 102, 2390 (2005).

${ }^{47}$ M. Ghibaudo, J. M. Di Meglio, P. Hersen, and B. Ladoux, Lab. Chip 11, 805 (2011).

${ }^{48}$ V. A. Schulte, Y. Hu, M. Diez, D. Bünger, M. Möller, and M. C. Lensen, Biomaterials 31, 8583 (2010).

${ }^{49}$ W. Mussard, N. Kebir, I. Kriegel, M. Esteve, and V. Semetey, Angew. Chem. Int. Ed. Engl. 50, 10871 (2011).

${ }^{50}$ See supplementary material at https://doi.org/10.1116/1.5024601 for colonization of hexagonal lattices by other epithelial cells, additional characterization in NOA and PEGDA 575 structures, cell adhesion on different surface chemistries, and set of raw data. 